\title{
CONVEX ORDERING PROPERTIES AND APPLICATIONS
}

\author{
Aurelia Florea, Eugen PĂLtăneA AND Dumitru BăLĂ
}

\begin{abstract}
A relevant application of the stochastic convex order is the well-known weighted Hermite-Hadamard inequality, where the weight is provided by a given probability distribution. Our goal is to show that, starting from such a fixed weight, we can fill the whole space between the Hermite-Hadamard bounds by highlighting some parametric families of probability distributions. Thus, we propose two alternative constructions based on the convex ordering properties.
\end{abstract}

Mathematics subject classification (2010): 26A51, 26B25, 26D10.

Keywords and phrases: Convex functions, Hermite-Hadamard inequality, convex order.

\section{REFERENCES}

[1] M. K. Bakula, J. PeČAriĆ And J. Perić, Extensions of the Hermite-Hadamard inequality with applications, Math. Inequal. Appl. 4 (2012), 899-921.

[2] J. L. BRENNER, H. Alzer, Integral inequalities for concave functions with applications to special functions, Proc. Roy. Soc. Edinburgh Sect. A 118 (1991), 173-192.

[3] J. DE LA CAL And J. CÁRCAMo, Multidimensional Hermite-Hadamard inequalities and the convex order, J. Math. Anal. Appl. 324 (2006), 248-261.

[4] L. FEJÉR, Über die Fourierreihen, II, Naturwiss. Anz. Ungar. Akad. Wiss. 24 (1906), 369-390.

[5] A. M. FinK, A best possible Hadamard Inequality, Math. Inequal. Appl. 1 (1998), 223-230.

[6] A. Florea AND C. P. Niculescu, A Hermite-Hadamard inequality for convex-concave symmetric functions, Bull. Soc. Sci. Math. Roum. 50 (2007), 149-156.

[7] V. I. Levin And S. B. SteČKin, Inequalities, Amer. Math. Soc. Transl. 14 (1960), 1-29.

[8] C. P. Niculescu And L.-E. Persson, Convex Functions and their Applications: A Contemporary Approach (CMS Books in Mathematics), Springer-Verlag New York Inc., New York, 2006.

[9] J. OHLIN, On a class of measures of dispersion with application to optimal reinsurance, ASTIN Bulletin 5 (1969), 249-266.

[10] A. OlbryŚ AND T. SZOSTOK, Inequalities of the Hermite-Hadamard type involving numerical differentiation formulas, arXiv preprint, arXiv: 1411.7859v1 [math.CA] (2014).

[11] T. RAJBA, On probabilistic characterizations of convexity and delta-convexity, Conference on Inequalities and Applications 14, September 7-13, 2014, Hajdúszoboszló (Hungary).

[12] T. RAJBA, On the Ohlin lemma for Hermite-Hadamard-Fejér type inequalities, Math. Inequal. Appl. 17 (2014), 557-571.

[13] T. RAJBA, On strong delta-convexity and Hermite-Hadamard type inequalities for delta-convex functions of higher order, Math. Inequal. Appl. 18 (2015), 267-293.

[14] M. Shaked And J. G. Shanthikumar, Stochastic Orders, Springer Series in Statistics, New York, 2007.

[15] T. Szostok, Levin Stečkin theorem and inequalities of the Hermite-Hadamard type, arXiv preprint, arXiv:1411.7708v1 [math.CA] (2014).

[16] T. Szostok, Ohlin's lemma and some inequalities of the Hermite-Hadamard type, Aequat. Math. (2014), DOI 10.1007/s00010-014-0286-2. 